\title{
Salmonella Typhimurium TTSS-2 deficient mig-14 mutant shows attenuation in immunocompromised mice and offers protection against wild-type Salmonella Typhimurium infection
}

Niladri Bhusan Pati', Vikalp Vishwakarma', Sathish kumar Selvaraj², Sabyasachi Dash¹, Bhaskar Saha², Neera Singh ${ }^{1}$ and Mrutyunjay Suar ${ }^{1 *}$

\begin{abstract}
Background: Development of Salmonella enterica serovar Typhimurium (S. Typhimurium) live attenuated vaccine carrier strain to prevent enteric infections has been a subject of intensive study. Several mutants of $S$. Typhimurium have been proposed as an effective live attenuated vaccine strain. Unfortunately, many such mutant strains failed to successfully complete the clinical trials as they were suboptimal in delivering effective safety and immunogenicity. However, it remained unclear, whether the existing live attenuated $S$. Typhimurium strains can further be attenuated with improved safety and immune efficacy or not.
\end{abstract}

Results: We deleted a specific non-SPI (Salmonella Pathogenicity Island) encoded virulence factor mig-14 (an antimicrobial peptide resistant protein) in ssaV deficient S. Typhimurium strain. The ssaV is an important SPI-II gene involved in Salmonella replication in macrophages and its mutant strain is considered as a potential live attenuated strain. However, fatal systemic infection was previously reported in immunocompromised mice like Nos $2^{-1-}$ and $11-10^{-1-}$ when infected with ssaV deficient S. Typhimurium. Here we reported that attenuation of S. Typhimurium ssaV mutant in immunocompromised mice can further be improved by introducing additional deletion of gene mig-14. The ssaV, mig-14 double mutant was as efficient as ssaV mutant, with respect to host colonization and eliciting Salmonellaspecific mucosal slgA and serum IgG response in wild-type C57BL/6 mice. Interestingly, this double mutant did not show any systemic infection in immunocompromised mice.

Conclusions: This study suggests that ssaV, mig-14 double mutant strain can be effectively used as a potential vaccine candidate even in immunocompromised mice. Such attenuated vaccine strain could possibly used for expression of heterologous antigens and thus for development of a polyvalent vaccine strain.

\section{Background}

Enteric infections represent a major threat to human health worldwide affecting both children and adults in developing and industrialized countries. These infections are caused by a number of pathogens including Salmonella, Shigella, Campylobacter species, Aeromonas, Plesio monas, Vibrio, Yersinia entercolitica, E. coli 0157:H7 and

\footnotetext{
* Correspondence: msbiotek@yahoo.com

'School of Biotechnology, KIIT University, Bhubaneswar 751024, Odisha, India Full list of author information is available at the end of the article
}

Rotavirus. Among these enteric pathogens, Salmonella enterica with more than 2500 serovars is considered as a key pathogen that can infect a wide range of host species and is the leading cause of acute gastroenteritis. The increased mortality, morbidity and limited availability of specific drugs against these infection demands an alternative to reduce the global disease burden. One such promising alternative is the development of live-attenuated vaccines. These vaccines are attenuated forms of the pathogen itself which can provide defense against the
C Biomed Central

(c) 2013 Pati et al.; licensee BioMed Central Ltd. This is an open access article distributed under the terms of the Creative Commons Attribution License (http://creativecommons.org/licenses/by/2.0), which permits unrestricted use, distribution, and reproduction in any medium, provided the original work is properly cited. 
infection from the same pathogen. In case of Salmonella, a facultative intracellular pathogen, specific cell mediated immune response is critical to control and clear the pathogen from the host [1-4]. In order to stimulate cellular immunity with higher efficacy, live attenuated Salmonella are preferred over the inactivated or killed vaccine candidates [5-7]. Ideally, a live attenuated vaccine strain should be able to withstand the host stress, provide defense against the concerned pathogen and should successfully colonize the host lymphoid tissues while retaining its avirulent nature. Researchers have established mice models in order to efficiently screen the possible vaccine attributes of genetically modified Salmonella enterica strains or their derivatives [8-12]. However, many live attenuated strains are known to develop systemic infection when administered to immune deficient individuals [13-15]. In order to prevent the systemic infection in immune-compromised patients, it is very crucial to attain sufficient attenuation. Many attenuated Salmonella vaccine strains carrying deletion mutation either in the metabolic gene or in the virulence factors have been developed but with a little success in the clinical trials [16]. This study primarily focuses on the development of an improved live-attenuated $S$. Typhimurium strain. A number of $S$. Typhimurium mutants developed, are known to elicit optimal immune response but showed reduced survival efficacy [17-26]. Earlier studies have shown that only a few such mutants have been actually tested in a pilot study in order to investigate their protection efficacy [27-29]. When tested, such a few proposed vaccine strains resulted in developing diseases in the hosts of variable immune status [20,30-32]. Therefore, the development of a safer immunogenic liveattenuated $S$. Typhimurium strain is a need of an hour [33] and can be accomplished by development of a suitably attenuated strain with an avirulent property in immunocompromised individuals. Previous studies have shown that TTSS-2 deficient $S$. Typhimurium strains were highly attenuated and conferred protection from further challenges of wild-type $S$. Typhimurium by eliciting $\mathrm{O}$-antigen specific serum IgG and secretory IgA in C57BL/6 mice [34-36]. In a recent study, the ssa $V$ mutant of $S$. Typhimurium was found to be virulent in immune compromised C57BL/6 mice devoid of Nos 2 and Il-10 gene [37]. These two mice strains were used as they lack key elements of the antibacterial defense like the inducible nitric oxide (NO) synthase, a reactive oxygen species generating enzyme and interleukin-10 gene [38]. In this study, we have also used CD40L KO mice to screen the attenuation of proposed vaccine strain. This particular mouse model is used as it is partially immunocompromised in terms of generation of different class of antibodies.

Virulence of TTSS-2 deficient $S$. Typhimurium in immunocompromised mice unveils the role of other factors favoring the replication and long-term survival of $S$. Typhimurium in host tissues. Mig-14, an antimicrobial peptide resistance protein, is one such important factor that supports the long-term persistence of Salmonella in the macrophages [39]. Mig-14 protein binds to the antimicrobial peptides like CRAMPS to protect Salmonella from antimicrobial peptides [40]. The presence of Mig-14 in the periplasmic localization inhibits the entry of antimicrobial peptides to the cytoplasm of the bacterium, eventually making macrophage a good niche for Salmonella to replicate and survive. This study proposes a diverse role for mig-14 in the survival of TTSS-2 deficient Salmonella in immunocompromised mice like Nos $2^{-/-}$, Il-10 ${ }^{-/-}$and $C D 40 L^{-/-}$and explores the possible potential of $S$. Typhimurium ssa $V$ and mig-14 double mutant as a safe vaccine carrier strain.

\section{Methods}

\section{Bacterial strains and plasmids}

Streptomycin resistant S. Typhimurium SB300 and Salmonella Enteritidis P125109 (S. Enteritidis) strains were taken as the wild-type controls [41,42]. Mutants MT5 (SB300; $\Delta s s a V)$ and MT4 (SB300; $\Delta s s a V, \Delta m i g-14)$ were generated by lambda red-mediated recombinase process [43]. Briefly, the host bacterial strain to be mutated was transformed with plasmid pKD46 and induced with arabinose $(10 \mathrm{mM})$. The kanamycin open reading frame was PCR-amplified from template plasmid pKD4 using gene specific knockout primers (Table 1). The cassette was introduced into host bacterial genome with the help of Exo, Bet and Gam proteins from induced pKD46 plasmid of host bacterial strain. The positive mutants were selected on LB agar plates supplemented with kanamycin $(50 \mu \mathrm{g} / \mathrm{ml})$ and mutation in the target gene was confirmed using gene specific confirmatory primers in combination with respective forward knock-out primer (Table 1). Later, the antibiotic cassette was flipped by plasmid pCP20 [43]. An ampicillin resistant plasmid (pM973) was used to maintain the ampicillin resistant trait in wild-type strain (SB300) while challenging vaccinated mice groups with wild-type $S$. Typhimurium [44]. The bacterial strains and the plasmids used in this study are listed in Table 2.

\section{Bacterial growth condition}

Luria-Bertani medium supplemented with $0.3 \mathrm{M}$ sodium chloride (SPI-1 inducing medium) was used to grow all the bacterial strains (Table 2 ) at $37^{\circ} \mathrm{C}$ for $12 \mathrm{~h}$. Strains were diluted 1:20 in fresh SPI-1 inducing medium and subcultured for another $4 \mathrm{~h}$ until the bacteria attained their early log phase. Bacterial cells were pelleted, washed in ice-cold phosphate buffered saline (PBS) and approximately $5 \times 10^{7} \mathrm{CFU}$ were suspended in $50 \mu \mathrm{l}$ cold PBS for use in the in vivo experiments. All the strains were tested 
Table 1 Primers used in the study

\begin{tabular}{ll}
\hline Fw-ssaV & AGT CGC AAT GCG TTC ATG GTT AG \\
Rw-ssaV & TC TTC ATT GTC CGC CAA CTC \\
KO-Fw-ssav & AAT AAA ATT TCT GGA GTC GCA ATG \\
& CGT TCA TGG TTA GGT GAG GGA TGT \\
GTA GGC TGG AGC TGC TT \\
KO-Rw-ssaV & GCA TCA ATT CAT TCT TCA TTG TCC \\
& TGA ATA TCC TCT TCG TTA GT AGG ATA \\
Conf-ssaV & GCA AAG CTT TGC TGC CAT TAA TCC \\
Fw-mig14 & GAG TT TGG TGA AAA TAC AAG AAG \\
Rw-mig14 & GTA TAG TGT AAG TGA ATT TCG AGT \\
& AAT TG \\
KO-Fw-mig14 & AGC AAA AAA ATA ATA CAA AAT AGC \\
& ATT TTC AGT AAG CTA AGT CAG TGT \\
GTA GGC TGG AGC TGC TT \\
KO-Rw-mig14 \\
GAA AAA TCT GGA CGT AAA AAA CAT \\
ATT TAC GTC CAG GCT TTC TTा ATA \\
TGA ATA TCC TCC TTA GT \\
CAT CAT CTG TTC CTG ACG CCA G \\
\hline
\end{tabular}

for growth attenuation for $16 \mathrm{~h}$ in $10 \mathrm{ml}$ of culture medium at $37^{\circ} \mathrm{C}$ with $150 \mathrm{rpm}$ under aerated conditions.

\section{Ethical statement}

All the animal experiments were performed in strict accordance with guidelines laid by the Institutional Animal Ethics Committee (IAEC) of National Centre for Cell Science (NCCS) Pune, India; Permit Number: 7/1999/ CPCSEA-09/03/1999.

\section{Mouse lines}

All experimental mice were specific pathogen free (SPF) C57BL/6 maintained in individually ventilated cages (IVC) (Tacket et al., 1992). Wild-type, Nos2 ${ }^{-/-}$(B6.129P2Nos2tm1Lau/J), Il-10 ${ }^{-/-} \quad\left(\mathrm{B} 6.129 \mathrm{P} 2-\mathrm{Il10} 0^{\mathrm{tm} 1 \mathrm{cgn}} / \mathrm{J}\right)$ and $\mathrm{CD}_{40 L^{-1-}}\left(\mathrm{B} 6.129 \mathrm{~S} 2-\mathrm{Cd} 40 \mathrm{lg}^{\mathrm{tm} 1 \mathrm{Imx}} / \mathrm{J}\right)$ mice were procured from Jackson Labs (Bar Harbor, ME) and bred in the
C57BL/6 background at the animal facility of National Center for Cell Sciences (NCCS), Pune, India.

\section{Mice infection experiment for assessment of strain attenuation}

The infection experiments were performed in streptomycin pretreated SPF mice in IVC as described earlier $[45,46]$. C57BL/6, $\mathrm{iNos}^{-/-}, \mathrm{Il}_{10^{-/-}}$and $\mathrm{CD}^{\mathrm{O} O \mathrm{OL}^{-/-}}$mice were pretreated orally with $50 \mathrm{mg}$ of streptomycin before infecting with wild-type and mutant strains. After $24 \mathrm{~h}$, mice were infected with $5 \times 10^{7} \mathrm{CFU}$ (oral gavage) of the corresponding bacterial strain (i.e. MT5, MT4 and SB300). The bacterial load in the cecum, mesenteric lymph nodes (mLNs), liver and spleen was determined by plating the respective tissue homogenates on MacConkey agar plates supplemented with appropriate antibiotics (Streptomycin, $50 \mu \mathrm{g} / \mathrm{ml}$; kanamycin, $50 \mu \mathrm{g} / \mathrm{ml}$; ampicillin, $100 \mu \mathrm{g} / \mathrm{ml}$ ). For statistical analysis, samples without bacterial counts were adjusted to the minimum detection level (10 CFU/ organ in the mLN, $20 \mathrm{CFU} /$ organ in the spleen, $10 / \mathrm{x}$ $\mathrm{CFU} / \mathrm{g}$, where $\mathrm{x}$ represents the net weight of the cecum content or feces collected). Cecal pathology of the infected mice was scored to analyze the degree of inflammation [45].

\section{Histopathological evaluation}

Segments of the cecum, colon and ileum were embedded in Optimum Cutting Temperature solution O.C.T. (Sakura Finetek Inc., USA), snap-frozen in liquid nitrogen, and stored at $-80^{\circ} \mathrm{C}$. The $5 \mu \mathrm{m}$ thick tissue sections were obtained on glass slides and stained with hematoxylin and eosin (H\&E) stains after drying for at least $2 \mathrm{~h}$ at room temperature. The stained cryosections were evaluated on the basis of a previously described scoring system for the quantitative analysis of cecal inflammation [45,47]. The sections were scored on the basis of the pathological changes that include sub-mucosal edema (0-3), polymorphonuclear leukocyte infiltration (0-4), loss of goblet cells $(0-3)$ and epithelial ulceration (0-3). The cumulative

Table 2 Bacterial strains and plasmids used in the study

\begin{tabular}{|c|c|c|c|}
\hline Strains & Genetic information & Background & References \\
\hline SB300 & Salmonella Typhimurium, $\mathrm{Sm}^{r}$ & Wild type & {$[41]$} \\
\hline M1525 & Salmonella Enteritidis 125109 wild type; Sm ${ }^{r}$ & Wild type & {$[42]$} \\
\hline MT4 & S. Typhimurium $\Delta s s a V, \Delta m i g-14 ; S m^{r}$ & SB300 & This study \\
\hline MT5 & S. Typhimurium $\Delta s s a V ; S m^{r}$ & SB300 & This study \\
\hline Plasmids & Relevant genotype (S) and/or phenotype (S) & Resistance & References \\
\hline pM973 & bla PssaH gfpmut2 plasmid with oripMB1 & $A m p^{r}$ & {$[44]$} \\
\hline pKD46 & Red recombinase expression plasmid; $P_{a r a B}$; oriR101 & $A m p^{r}$ & {$[43]$} \\
\hline pKD4 & Template plasmid; FRT-aphT-FRT & $\mathrm{Km}^{\mathrm{r}}$ & {$[43]$} \\
\hline pCP20 & FLP recombinase expression plasmid & $C m^{r}, A m p p^{r}$ & {$[43]$} \\
\hline
\end{tabular}


pathological scores ranged from 0 to 13 with arbitrary units covering the inflammation levels that included intact intestine without any sign of inflammation (pathoscore 0); minimal sign of inflammation (pathoscore 1-2), which is commonly found in the ceca of specific pathogen-free mice and generally not considered as a pathological feature; slight inflammation as a minimal sign of tissue pathology (pathoscore 3-4); moderate inflammation (pathoscore 5-8); and significant inflammation (pathoscore 9-13).

\section{Vaccination and challenge experiment}

For vaccination study, three groups of wild type C57BL/6 mice ( $n=10$; each group) were pretreated with streptomycin according to the protocol described earlier [34]. Mice groups ( 3 groups; $\mathrm{n}=5$ mice each group) were vaccinated with MT5, MT4 strains and PBS respectively; the mice group treated with PBS served as a negative control group [34,48]. Fecal samples from each mice group were collected weekly and plated on MacConkey agar plate for analysis of fecal shedding of the vaccine strain. At day 30 post vaccination (p.v.), the histopathology of cecal mucosa and bacterial loads of different tissues of vaccinated mice ( $n=5$; each group) were analyzed. Further, the gut wash and serum samples of vaccinated mice were collected to assess serum IgG and gut secretory IgA (sIgA) by Western blot. The remaining mice $(n=5)$ from each vaccinated group were treated with ampicillin ( $25 \mathrm{mg}$ by gavage) and challenged after $24 \mathrm{~h}$ with wild-type $S$. Typhimurium (SB300; 200 CFU) harboring ampicillin resistant plasmid pM973. The colonization efficiency of the challenged strain was evaluated at various host sites at day 3 post challenge (p.c.).

\section{Evaluation of serum and gut antibody response}

To measure the mucosal immune response, serum IgG and secretory gut IgA responses were quantified by Western blot as described previously $[34,48]$. Serum and gut washes were collected at day 30 p.v from MT5 and MT4 immunized mice and the PBS treated control mice. The protein fractions of lysates from the overnight-grown $S$. Typhimurium wild-type strain (SB300), ssa $V$ mutant (MT5), ssaV and mig-14 double mutant (MT4) and S. Enteritidis P125109 (M1525) wild-type strain were separated on polyacrylamide gels and transferred to nitrocellulose membrane. The membrane was treated with suitably diluted serum sample or gut washes followed by incubation with conjugated $\alpha$-mouse IgG (for serum; Santa cruz) and $\alpha$-mouse IgA (for gut wash; Santa cruz). The blots were developed by ECL kit (Thermo Scientific).

\section{Statistical analysis}

Statistical analyses were performed using the two-way ANOVA (GraphPad Prism 5). p $<0.05$ was considered statistically significant.

\section{Results and discussion}

Additional mig-14 mutation in S. Typhimurium ssaV mutant shows significant attenuation in immunocompromised mice

The attenuation of MT5 and MT4 strains in various immunocompromised mice was analyzed by normal infection experiment at day 4 p.i. In our initial observations, equivalent loads of MT5 and MT4 strains were detected in the cecal content of $N o s 2^{-/-}, \mathrm{Il}-10^{-/-}$mice (Figure 1A) whereas, MT4 showed reduced colonization in spleen and liver (Figure 1B, C and D) as compared to MT5. Similar experiment was carried out to assess the performance of MT4 in wt $\mathrm{C} 57 \mathrm{BL} / 6$ and $C D 40 \mathrm{~L}^{-/-}$ mice. It was observed that neither MT4 nor MT5 colonized spleen and liver of $C D 40 L^{-/-}$and wild-type C57BL/6 mice (Figure 1C-D). However, MT4 (ssaV, mig-14 mutant) colonized the mLN of wild-type mice as efficiently as MT5 (ssaV mutant) (Figure 1B). We also tested the attenuation profile in terms of competitive index of mig14::aphT single mutant against wild-type $S$. Typhimurium strain; it was appreciable that the mig14::aphT single mutant has reduced ability to colonize to systemic sites (Additional file 1: Figure S1 and Additional file 1: Figure S2); however, this reduced colonization in liver and spleen was not as sharp as in case of C57BL/6 mice infected with ssa V mutant MT5 (compare Additional file 1: Figure S2 with Figure $1 C, D$ ). Overall the data demonstrates that the deletion of mig-14 in the ssa $V$ knockout background does not allow $S$. Typhimurium to colonize the systemic sites like liver and spleen in severely immunocompromised mice (Figure $1 \mathrm{C}$ and D).

\section{MT4 protects wild-type C57BL/6 mice when challenged with wild-type $S$. Typhimurium}

The immunogenic potential of MT4 in wild-type C57BL/6 mice was analyzed by previously established vaccination and challenge protocol using TTSS-2 deficient $S$. Typhimurium strain [34]. Three groups of wild-type C57BL/6 mice were vaccinated with MT4 $(n=10), \operatorname{MT5}(n=10)$ and PBS (negative control; $\mathrm{n}=10$ ). The fecal shedding was analyzed as a measure of cecal colonization during vaccination period. Both, MT5 and MT4 strains reached a bacterial load of $\sim 10^{9} \mathrm{CFU} / \mathrm{g}$ (of cecal content) in the gut lumen at the day 1 p.v.; however, the bacterial loads slightly declined at day 14 and day 28 p.v. (Figure 2A). Half the number of vaccinated mice (MT5, $n=5 ;$ MT4, $\mathrm{n}=5$; PBS, $\mathrm{n}=5$ ) were sacrificed to analyze cecal inflammation and the colonization levels in different systemic sites at day 30 p.i. With both the strains, cecum colonization was maintained up to $\sim 10^{7-9} \mathrm{CFU} / \mathrm{g}$. The bacterial load in mLN was lower as compared to the acute infection experiments (compare Figure $1 \mathrm{~B}$ to $2 \mathrm{~B}$ ) whereas cecal mucosa did not show any sign of disease (Figure $2 \mathrm{C}$ ). The remaining mice were analyzed for protection 

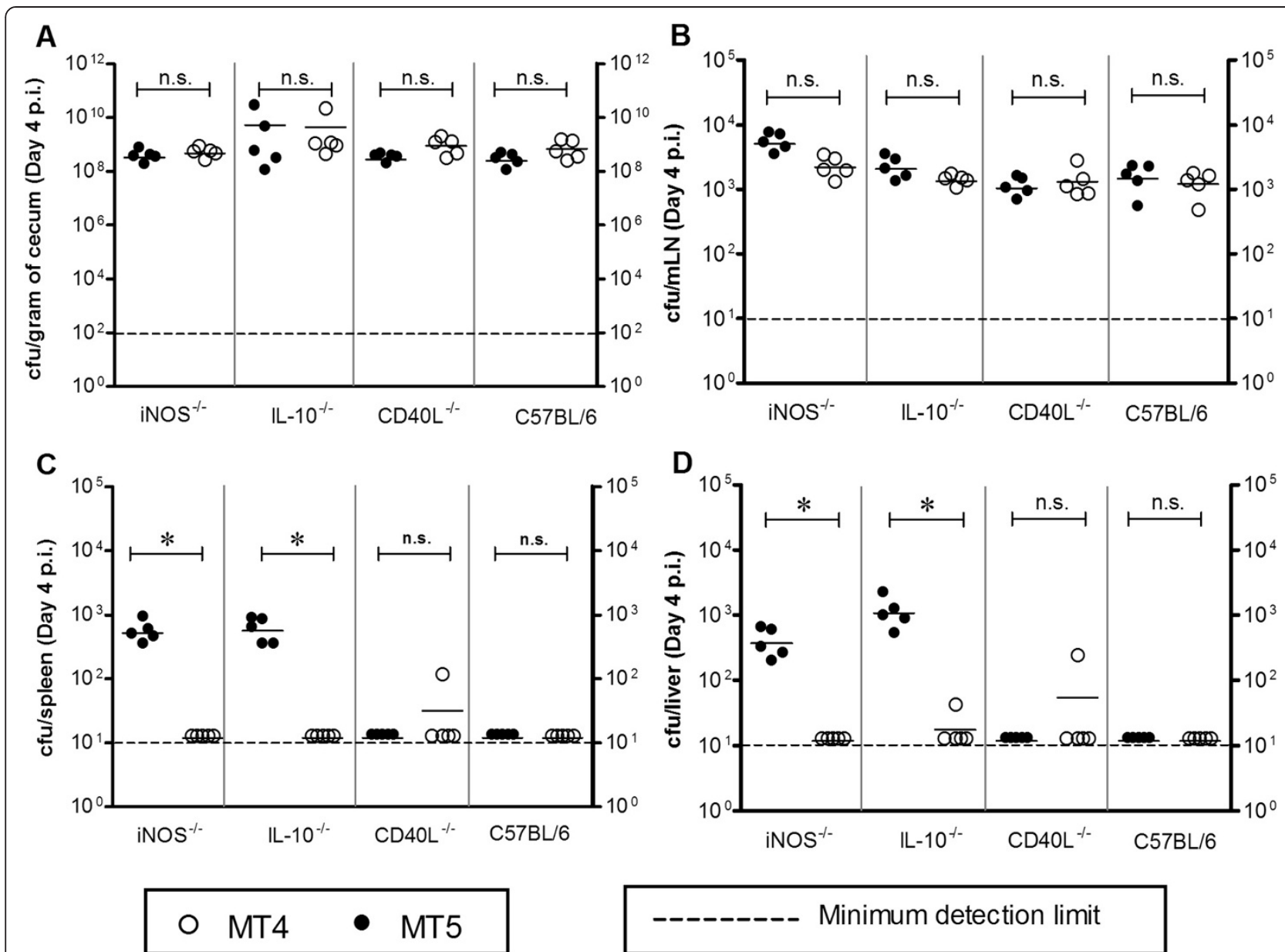

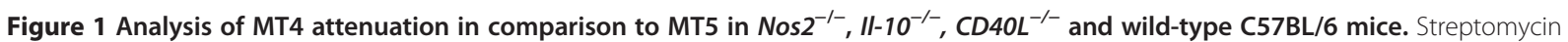
pretreated mice were infected either with MT5 or MT4 (5x107 CFU by gavage; $n=5$ mice). Bacterial loads in cecum content (A), $m L N(B), s p l e e n$ (C) and liver (D) were assessed by plating at day 4 p.i... n.S., statistically not significant; ${ }^{*}$, statistically significant $(p<0.05$, Two-way ANOVA).

against a challenge with wild-type $S$. Typhimurium. At day 30 p.v., the remaining vaccinated mice (MT4, $\mathrm{n}=5$; MT5, $\mathrm{n}=5$; PBS, $\mathrm{n}=5$ ) were treated with $20 \mathrm{mg}$ of ampicillin to remove regrown gut flora and any residual vaccine strain. Mice groups were then challenged with wild-type $S$. Typhimurium at day $31^{\text {st }}(200 \mathrm{CFU}$ by gavage). The wild-type $S$. Typhimurium was able to colonize the lumen efficiently and reached the carrying capacity by day 3 p.c. in all three immunized groups (Figure 3A). Mice in the PBS treated control group suffered from severe enteropathy (Figure 3B). In contrast, the mice immunized with MT5 and MT4 strains did not show any signs of mucosal inflammation (Figure 3B). Furthermore, spleen and liver colonization by wild-type $S$. Typhimurium was significantly reduced in both the vaccinated groups $(\mathrm{p}<0.05$; Figure $3 \mathrm{~A})$. Thus, the data indicates that MT4 strain conferred equivalent level of protection from Salmonella inflicted disease as MT5 strain.
Mice immunized with MT4 and MT5 showed equivalent response for both luminal $\lg A$ and serum specific lgG

Earlier it has been established that immune-protection against $S$. Typhimurium is based on $\mathrm{O}$-antigen specific luminal sIgA along with serum IgA, IgM and IgG responses [34]. To validate the immunogenic potential of MT4, the antibody titers of IgG from serum and IgA from gut wash samples of mice vaccinated with MT4 and MT5 strains were detected by western blotting at the end of the day 30 p.v. (Figure 4). This experiment relies on the specific antibody binding to specific antigens of the bacterium (wild-type $S$. Typhimurium) as compared to a bacterium of different serovar (wild-type $S$. Enteritidis). The intestinal wash and serum samples from mice vaccinated with either MT5 or MT4 exhibited equivalent antibody response of Salmonella specific serum IgG and luminal secretory IgA. We additionally tested the antibody response through flow cytometry analysis and the data supported the finding that MT4 or MT5 vaccination exhibits equivalent antibody 


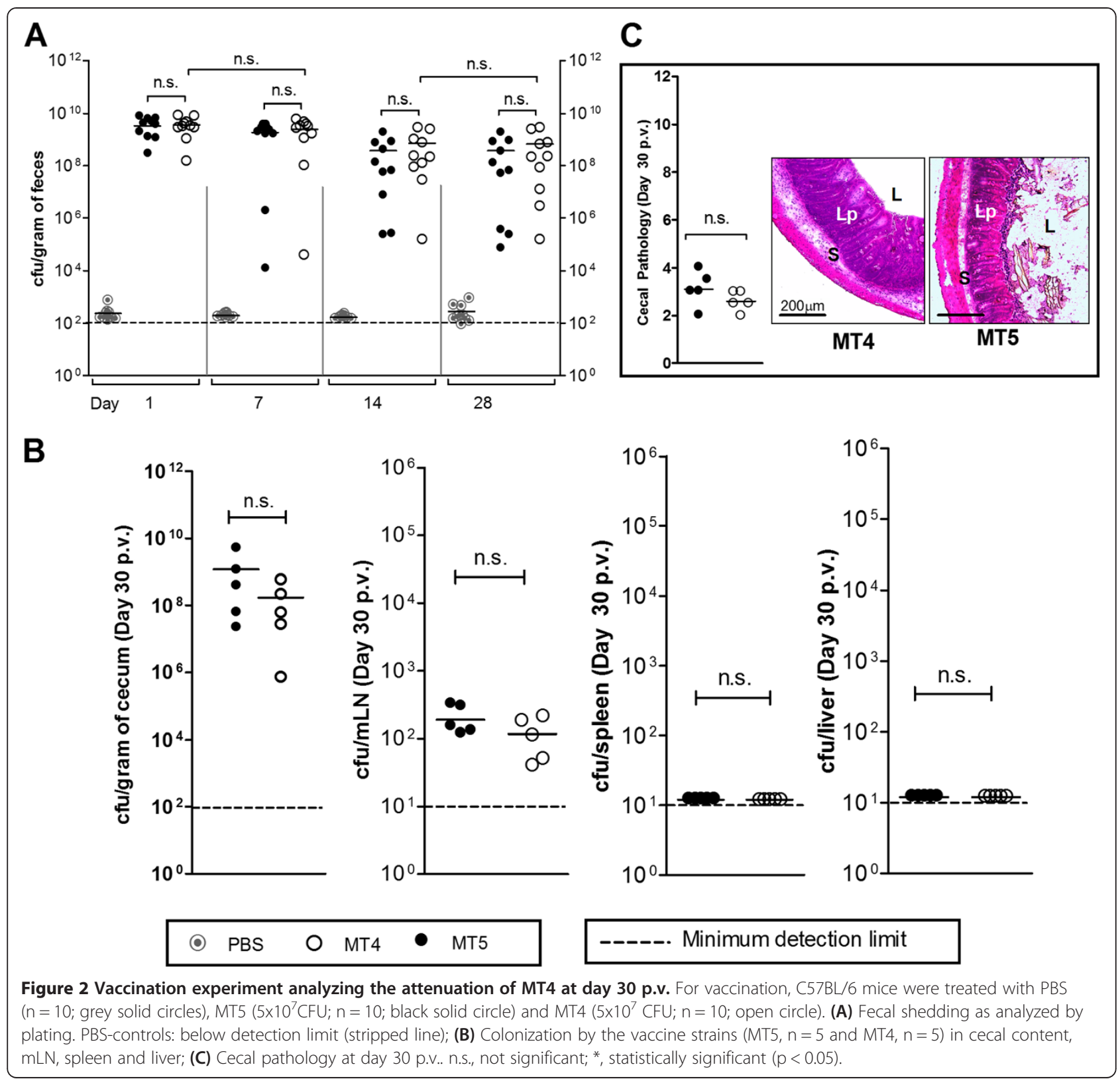

response (Additional file 1: Figure S4). The T-cytotoxic and T-helper cells play a critical role in the clearance of Salmonella as well as in the production of specific antibodies during the late phase of infection. We analyzed the effect of MT5 and MT4 strains on T-cell population of the mesenteric lymph node. We quantified the $\mathrm{CD} 4^{+}$and $\mathrm{CD}^{+}$ $\mathrm{T}$-cell population recovered from the $\mathrm{mLN}$ of the vaccinated mice after day 30 p.v. The T-cell population were analyzed by flowcytometry and found to be almost equally populated in the vaccinated mice but significantly more in comparison to the PBS treated mice (Additional file 1: Figure S3). This gives a sign that, the MT4 strain has an ability to colonize and induce T-cell mediated innate and adaptive immune response in the wild-type C57BL/6 mice.

\section{Conclusions}

$S$. Typhimurium with a nonfunctional SPI-2 is considered as an avirulent and a potential vaccine strain [37]. In this study we have experimentally proved that $S$. Typhimurium diarrhea vaccine strain with nonfunctional SPI-2 system can be further attenuated without impeding the immunogenicity in immunocompromised hosts. We additionally mutated mig-14 in ssaV deficient $S$. Typhimurium strain. The ssaV, mig-14 double mutant was found to be highly attenuated in wild-type $\mathrm{C} 57 \mathrm{BL} / 6$ mice and in immuno-

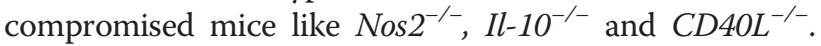
These transgenic immunocompromised mice were selected for this study because of their high susceptibility to different infections $[33,49,50]$. One of the characteristic 


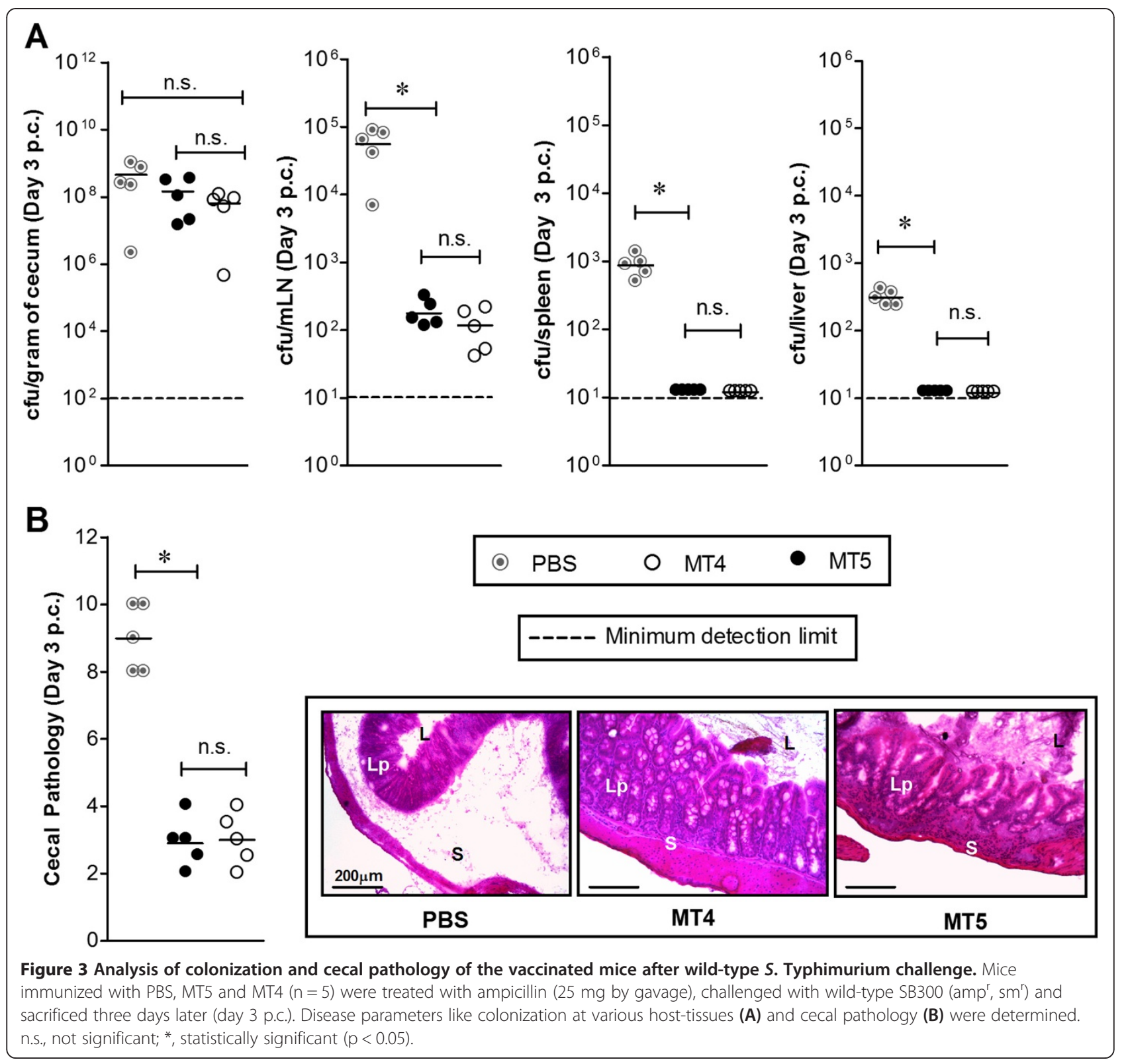

features of Salmonella infections in humans is that few infected individuals can become chronic carriers. Such individuals comprise about $1-6 \%$ of the total infected population $[19,24]$ acting as reservoirs, and restricting the pathogen within the human populations. Previous studies have established that the successive progression of hostadapted Salmonella species has led to an increased virulence because of their association with the host along with increased invasiveness and long-term persistence [51,52]. The virulence factors essential for long-term persistence of the pathogen in their respective hosts are therefore likely to be important for its evolutionary success.

Mig-14 is an important factor for Salmonella resistance to IFN- $\gamma$-mediated host responses and to different anti-microbial peptide during the establishment of infection as well as survival in the macrophages [16]. It has also been reported that mig-14 mutant can establish an infection but cannot persist for longer periods in the host system [53]. These reports support the contribution of Mig-14 in Salmonella long-term virulence. Although the mechanism of Mig-14 action is not completely established, the binding of Mig-14 deficient Salmonella to cathelinrelated antimicrobial peptide (CRAMP) proves its active involvement in Salmonella antimicrobial peptide resistance [40]. Mechanistically, Mig-14 protein is a periplasmic protein which is tightly associated with the inner membrane of Salmonella [53]. The transmission electron microscopy study has revealed that the primary site of host CRAMP 


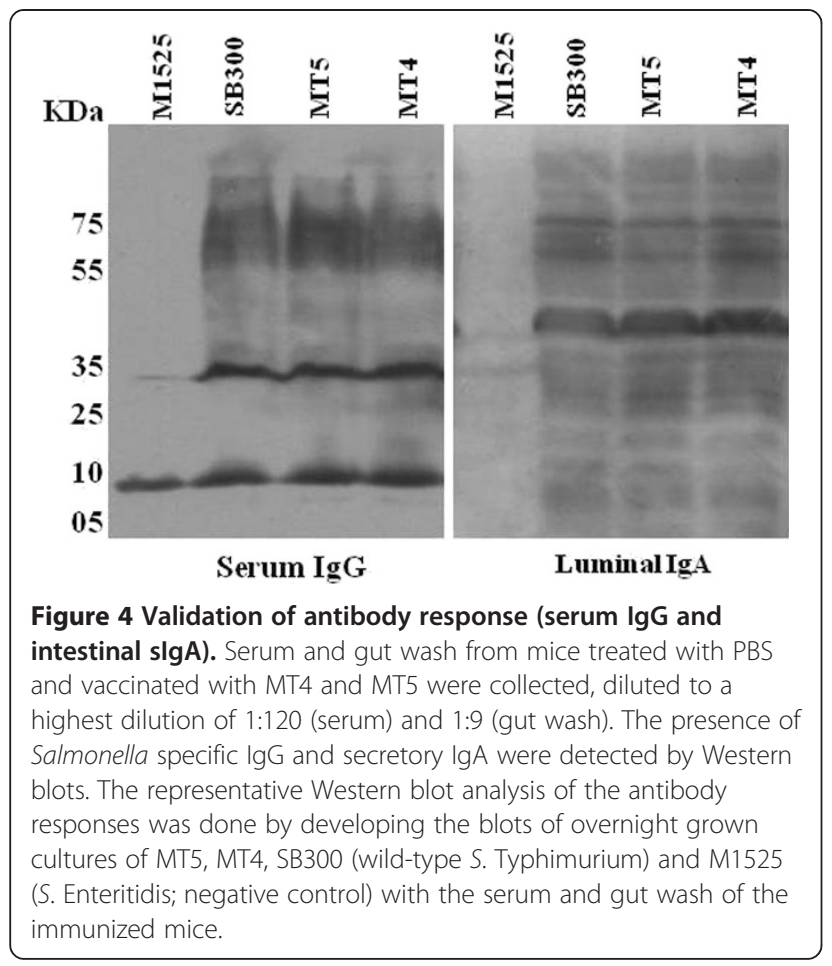

activity is the bacterial cytoplasm. Study of inner membrane localization of Mig-14 and cytoplasmic CRAMP activity, possibly suggests the role of Mig-14 in preventing penetration of CRAMP into the cytoplasm [40]. Taken together, these reports explain contribution of mig-14 towards pathogen survival by encountering host inflammatory responses and promoting both acute and persistent bacterial infection. Therefore, in the present study, mig-14 was taken as an important virulence factor to be knocked out from the existing live attenuated strain (MT5) with the goal to improve the attenuation attributes in immunocompromised mice.

In this study, we have assessed the degree of attenuation of S. Typhimurium ssaV mutant (MT5) and ssaV, mig-14 double mutant (MT4) in immunocompromised mice, by infecting these two strains to $\mathrm{Nos}^{-/-}, \mathrm{Il}-10^{-/-}$ and $C D 40 L^{-/-}$C57BL/6 mice. The day 4 p.i. observation showed a high degree of systemic attenuation of MT4 (ssaV, mig-14) strain in $\mathrm{Nos}^{-/-}, \mathrm{Il}-10^{-/-}$mice in comparison to the MT5 (ssaV) strain. On the other hand MT5 and MT4 strains were equally attenuated in $C D 4 O L^{-/-}$mice. Interestingly, MT4 strain also retained its capacity to colonize the mesenteric lymph node of Nos $2^{-/-}, \mathrm{Il}-10^{-/-}$and $\mathrm{CD}^{-10 \mathrm{~L}^{-/-}}$mice, demonstrating its ability to access the mLN but not the systemic sites. The in vivo data showed that the attenuation of MT4 in immunocompromised mice could be due to the absence of mig-14 in ssaV deficient $S$. Typhimurium. Furthermore, the MT4 and MT5 strains were used to vaccinate the wild-type C57BL/6 mice. Results showed that none of the mice developed cecal inflammation at day 30 p.v. However, both the strains (MT5 and MT4) equally colonized the gut lumen of vaccinated mice groups. Apart from this, at 30 day p. v., neither of the strain was found in the systemic organs which diminishes the possibility of late systemic dissemination and associated disease symptoms. Interestingly, apart from MT5, we also found a small population of MT4 strain in the mesenteric lymph node of the immunized mice, showing the potential of MT4 to stay in the lymphoid tissue for a longer period. In a challenge experiment, the vaccinated mice were protected when challenged with wild-type $S$. Typhimurium, however, the PBS treated mice developed significant inflammation and systemic dissemination of S. Typhimurium during subsequent Salmonella challenge.

In conclusion, the MT4 live-attenuated S. Typhimurium strain provides an efficient antibody mediated immune response which can protect even immunocompromised hosts from lethal infection of Salmonella. Specific antibody response to any protein antigens requires the involvement of both $\mathrm{CD}^{+}$and $\mathrm{CD} 8^{+}$T-cells along with the B-cells. The T-cell dependent antigens require the involvement of $\mathrm{T}$-cells for the adaptive immune response. T helper $\left(\mathrm{CD} 4^{+}\right)$cells play a vital role in stimulating the $\mathrm{B}$-cells for the production of pathogen specific antibody via clonal propagation. Additionally, the activated $\mathrm{CD}^{+}$and $\mathrm{CD}^{+}{ }^{+}$-cells are the major producers of INF- $\gamma$ which further activates the tissue and blood macrophages. As T-cell contributes to the cell mediated immune response, it is important to estimate the T-cell propagation during the course of Salmonella infection. In this study we have additionally estimated $\mathrm{CD}_{4}^{+}$and $\mathrm{CD}^{+}{ }^{+} \mathrm{T}$-cells from the $\mathrm{mLN}$ of the immunized mice. $\mathrm{CD}^{+}$and $\mathrm{CD}^{+}{ }^{+}$T-cell population of the mice immunized with MT4 strain found to be comparable with the mice immunized with MT5 strain. Hence, it concludes that the MT4 strain retains its ability to induce the classical innate and adaptive immune response even after a strong attenuation. Therefore, we propose that incorporating additional "safety" features such as the deletion of mig-14 can be of a general interest for the design of new super live attenuated $S$. Typhimurium strain. This attenuated strain could also be used for developing the recombinant vaccine against other enteric pathogens.

\section{Additional file}

\footnotetext{
Additional file 1: Figure S1. Evaluation of attenuation profile of mig 14: aphT mutant in comparison to wild-type strain of Salmonella Typhimurium. Competitive index profile of mig-14::aphT mutant when compared against wild-type strain. n.s. $=$ not significant; ${ }^{*}=p<0.05$ ). Figure S2. Infection profile of mig14::aphT mutant in comparison to wild-type strain of Salmonella Typhimurium .Infection profile and systemic attenuation of mig14::aphT mutant. Bar indicates $200 \mu \mathrm{m}$. n.s. $=$ not significant; ${ }^{*}=p<0.05$ ). Figure S3. Flowcytometric analysis of
} 
T-cell population after Salmonella infection. The whole cells were isolated from the $\mathrm{mLN}$ of the vaccinated mice. The cells were then suspended in appropriate medium and processed for flow cytometric analysis (see materials and methods). The cells were detected by using specific conjugated antibodies against specific T-cells. Figure S4. Luminal and serum specific antibody responses in mice immunized with MT5 and MT4. Serum and gut wash from mice treated with PBS and vaccinated with MT4 and MT5 were collected, diluted to a highest dilution of 1:120 (serum) and 1:9 (gut wash). The presence of Salmonella specific lgG and secretory IgA were detected by bacterial flow cytometric (A) and Western blot (B). Each coloured line indicates data obtained from individual mice of respective group. The representative Western blot analysis of the antibody responses was done by developing the blots from the overnight cultures of MT5, MT4, SB300 (wt S. Typhimurium) and M1525 (S. Enteritidis; negative control) by using the sera and gut luminal slgA of the immunized mice.

\section{Competing interests}

The authors declare that they have no competing interests.

\section{Authors' contributions}

NB, BS, MS designed the experiments; NP, W, SS performed the experiments; NB, NS, MS wrote the manuscript; W, NS, SD, MS reviewed and edited the manuscript; BS provided the animal facility; MS provided the chemicals and consumables for this study. All authors read and approved the final manuscript.

\section{Acknowledgements}

This work was supported by the grant from Department of Biotechnology, Govt. of India (Project No. BT/PR14489/Med/29/207/2010). We thank Himanshu Singh Chandel for his support during the experiments.

\section{Author details}

'School of Biotechnology, KIIT University, Bhubaneswar 751024, Odisha, India.

${ }^{2}$ National Centre for Cell Science, Ganeshkhind, Pune, India.

Received: 14 May 2013 Accepted: 24 September 2013

Published: 22 October 2013

\section{References}

1. Okamura M, Lillehoj HS, Raybourne RB, Babu US, Heckert RA: Cell-mediated immune responses to a killed Salmonella enteritidis vaccine: lymphocyte proliferation, T-cell changes and interleukin-6 (LL-6), IL-1, IL-2, and IFN-gamma production. Comp Immunol Microbiol Infect Dis 2004, 27(4):255-272.

2. Thatte J, Rath $\mathrm{S}, \mathrm{Bal} \mathrm{V}$ : Analysis of immunization route-related variation in the immune response to heat-killed Salmonella typhimurium in mice. Infect Immun 1995, 63(1):99-103.

3. Penha Filho RA, Moura BS, de Almeida AM, Montassier HJ, Barrow PA, Berchieri Junior A: Humoral and cellular immune response generated by different vaccine programs before and after Salmonella Enteritidis challenge in chickens. Vaccine 2012, 30(52):7637-7643.

4. Crhanova M, Hradecka H, Faldynova M, Matulova M, Havlickova H, Sisak F, Rychlik I: Immune response of chicken gut to natural colonization by gut microflora and to Salmonella enterica serovar enteritidis infection. Infect Immun 2011, 79(7):2755-2763.

5. Silva EN, Snoeyenbos GH, Weinack OM, Smyser CF: Studies on the use of $9 R$ strain of Salmonella gallinarum as a vaccine in chickens. Avian Dis 1981, 25(1):38-52.

6. Roland K, Tinge S, Warner E, Sizemore D: Comparison of different attenuation strategies in development of a Salmonella hadar vaccine. Avian Dis 2004, 48(3):445-452.

7. Robertsson JA, Lindberg AA, Hoiseth S, Stocker BA: Salmonella typhimurium infection in calves: protection and survival of virulent challenge bacteria after immunization with live or inactivated vaccines. Infect Immun 1983, 41(2):742-750.

8. Vladoianu IR, Dubini F: Experimental model of oral antityphoid vaccination with live streptomycin-dependent Salmonella typhimurium in C57BL/6 mice. J Hyg (Lond) 1975, 75(2):215-218.

9. Totemeyer S, Kaiser P, Maskell DJ, Bryant CE: Sublethal infection of C57BL/ 6 mice with Salmonella enterica Serovar Typhimurium leads to an increase in levels of Toll-like receptor 1 (TLR1), TLR2, and TLR9 mRNA as well as a decrease in levels of TLR6 mRNA in infected organs. Infect Immun 2005, 73(3):1873-1878.

10. Vishwakarma V, Pati NB, Chandel HS, Sahoo SS, Saha B, Suar M: Evaluation of Salmonella enterica serovar Typhimurium TTSS-2 deficient fur mutant as safe live-attenuated vaccine candidate for immunocompromised mice. PLoS One 2012, 7(12):e52043.

11. Toobak H, Rasooli I, Talei D, Jahangiri A, Owlia P, Darvish Alipour Astaneh S: Immune response variations to Salmonella enterica serovar Typhi recombinant porin proteins in mice. Biologicals 2013, 41(4):224-230.

12. Chaudhuri RR, Peters SE, Pleasance SJ, Northen H, Willers C, Paterson GK, Cone DB, Allen AG, Owen PJ, Shalom G, et al: Comprehensive identification of Salmonella enterica serovar typhimurium genes required for infection of BALB/c mice. PLOS Pathog 2009, 5(7):e1000529.

13. Cheminay C, Hensel M: Rational design of Salmonella recombinant vaccines. Int J Med Microbiol 2008, 298(1-2):87-98.

14. Gilks CF, Brindle RJ, Otieno LS, Simani PM, Newnham RS, Bhatt SM, Lule GN, Okelo GB, Watkins WM, Waiyaki PG, et al: Life-threatening bacteraemia in HIV-1 seropositive adults admitted to hospital in Nairobi, Kenya. Lancet 1990, 336(8714):545-549.

15. Gordon MA, Banda HT, Gondwe M, Gordon SB, Boeree MJ, Walsh AL, Corkill JE, Hart CA, Gilks CF, Molyneux ME: Non-typhoidal salmonella bacteraemia among HIV-infected Malawian adults: high mortality and frequent recrudescence. Aids 2002, 16(12):1633-1641.

16. Raupach B, Kaufmann SH: Bacterial virulence, proinflammatory cytokines and host immunity: how to choose the appropriate Salmonella vaccine strain? Microbes Infect 2001, 3(14-15):1261-1269.

17. Dunstan SJ, Simmons CP, Strugnell RA: Comparison of the abilities of different attenuated Salmonella typhimurium strains to elicit humoral immune responses against a heterologous antigen. Infect Immun 1998, $66(2): 732-740$

18. Garmory HS, Leary SE, Griffin KF, Williamson ED, Brown KA, Titball RW: The use of live attenuated bacteria as a delivery system for heterologous antigens. J Drug Target 2003, 11(8-10):471-479.

19. Hohmann EL, Oletta CA, Miller SI: Evaluation of a phoP/phoQ-deleted, aroA-deleted live oral Salmonella typhi vaccine strain in human volunteers. Vaccine 1996, 14(1):19-24.

20. Tacket CO, Kelly SM, Schodel F, Losonsky G, Nataro JP, Edelman R, Levine MM Curtiss R 3rd: Safety and immunogenicity in humans of an attenuated Salmonella typhi vaccine vector strain expressing plasmid-encoded hepatitis B antigens stabilized by the Asd-balanced lethal vector system. Infect Immun 1997, 65(8):3381-3385.

21. Chatfield SN, Strugnell RA, Dougan G: Live Salmonella as vaccines and carriers of foreign antigenic determinants. Vaccine 1989, 7(6):495-498.

22. Curtiss R 3rd, Wanda SY, Gunn BM, Zhang X, Tinge SA, Ananthnarayan V, Mo H, Wang S, Kong W: Salmonella enterica serovar typhimurium strains with regulated delayed attenuation in vivo. Infect Immun 2009, 77(3):1071-1082.

23. Heithoff DM, Enioutina EY, Daynes RA, Sinsheimer RL, Low DA, Mahan MJ: Salmonella DNA adenine methylase mutants confer cross-protective immunity. Infect Immun 2001, 69(11):6725-6730

24. Matsui H, Suzuki M, Isshiki Y, Kodama C, Eguchi M, Kikuchi Y, Motokawa K, Takaya A, Tomoyasu T, Yamamoto T: Oral immunization with ATP-dependent protease-deficient mutants protects mice against subsequent oral challenge with virulent Salmonella enterica serovar typhimurium. Infect Immun 2003, 71(1):30-39.

25. McFarland WC, Stocker BA: Effect of different purine auxotrophic mutations on mouse-virulence of a Vi-positive strain of Salmonella dublin and of two strains of Salmonella typhimurium. Microb Pathog 1987, 3(2):129-141.

26. Miller SI, Loomis WP, Alpuche-Aranda C, Behlau I, Hohmann E: The PhoP virulence regulon and live oral Salmonella vaccines. Vaccine 1993, 11(2):122-125.

27. Angelakopoulos $\mathrm{H}$, Hohmann EL: Pilot study of phoP/phoQ-deleted Salmonella enterica serovar typhimurium expressing Helicobacter pylori urease in adult volunteers. Infect Immun 2000, 68(4):2135-2141.

28. Hindle Z, Chatfield SN, Phillimore J, Bentley M, Johnson J, Cosgrove CA, Ghaem-Maghami M, Sexton A, Khan M, Brennan FR, et al: Characterization of Salmonella enterica derivatives harboring defined aroC and Salmonella pathogenicity island 2 type III secretion system (ssaV) mutations by immunization of healthy volunteers. Infect Immun 2002, 70(7):3457-3467. 
29. Toso JF, Gill VJ, Hwu P, Marincola FM, Restifo NP, Schwartzentruber DJ, Sherry RM, Topalian SL, Yang JC, Stock F, et al: Phase I study of the intravenous administration of attenuated Salmonella typhimurium to patients with metastatic melanoma. J Clin Oncol 2002, 20(1):142-152.

30. Hone DM, Tacket CO, Harris AM, Kay B, Losonsky G, Levine MM: Evaluation in volunteers of a candidate live oral attenuated Salmonella typhi vector vaccine. J Clin Invest 1992, 90(2):412-420.

31. Dilts DA, Riesenfeld-Orn I, Fulginiti JP, Ekwall E, Granert C, Nonenmacher Brey RN, Cryz SJ, Karlsson K, Bergman K, et al: Phase I clinical trials of aroA aroD and aroA aroD htrA attenuated S. typhi vaccines; effect of formulation on safety and immunogenicity. Vaccine 2000, 18(15):1473-1484.

32. Kotton CN, Lankowski AJ, Scott N, Sisul D, Chen LM, Raschke K, Borders G, Boaz M, Spentzou A, Galan JE, et al: Safety and immunogenicity of attenuated Salmonella enterica serovar Typhimurium delivering an HIV-1 Gag antigen via the Salmonella Type III secretion system. Vaccine 2006, 24(37-39):6216-6224.

33. Kwon YM, Cox MM, Calhoun LN: Salmonella-based vaccines for infectious diseases. Expert Rev Vaccines 2007, 6(2):147-152.

34. Endt K, Stecher B, Chaffron S, Slack E, Tchitchek N, Benecke A, Van Maele L, Sirard JC, Mueller AJ, Heikenwalder M, et al: The microbiota mediates pathogen clearance from the gut lumen after non-typhoidal Salmonella diarrhea. PLoS Pathog 2010, 6(9):e1001097.

35. Hensel M, Shea JE, Gleeson C, Jones MD, Dalton E, Holden DW: Simultaneous identification of bacterial virulence genes by negative selection. Science 1995, 269(5222):400-403.

36. Shea JE, Beuzon CR, Gleeson C, Mundy R, Holden DW: Influence of the Salmonella typhimurium pathogenicity island 2 type III secretion system on bacterial growth in the mouse. Infect Immun 1999, 67(1):213-219.

37. Periaswamy B, Maier L, Vishwakarma V, Slack E, Kremer M, AndrewsPolymenis HL, McClelland M, Grant AJ, Suar M, Hardt WD: Live attenuated S. Typhimurium vaccine with improved safety in immuno-compromised mice. PLoS One 2012, 7(9):e45433.

38. Fang FC: Antimicrobial reactive oxygen and nitrogen species: concepts and controversies. Nat Rev Microbiol 2004, 2(10):820-832.

39. Valdivia RH, Cirillo DM, Lee AK, Bouley DM, Falkow S: mig-14 is a horizontally acquired, host-induced gene required for salmonella enterica lethal infection in the murine model of typhoid fever. Infect Immun 2000, 68(12):7126-7131.

40. Brodsky IE, Ghori N, Falkow S, Monack D: Mig-14 is an inner membraneassociated protein that promotes Salmonella typhimurium resistance to CRAMP, survival within activated macrophages and persistent infection. Mol Microbiol 2005, 55(3):954-972.

41. Hoiseth SK, Stocker BA: Aromatic-dependent Salmonella typhimurium are non-virulent and effective as live vaccines. Nature 1981, 291(5812):238-239.

42. Vishwakarma V, Periaswamy B, Bhusan Pati N, Slack E, Hardt WD, Suar M: A novel phage element of Salmonella enterica serovar Enteritidis P125109 contributes to accelerated type III secretion system 2-dependent early inflammation kinetics in a mouse colitis model. Infect Immun 2012, 80(9):3236-3246.

43. Datsenko KA, Wanner BL: One-step inactivation of chromosomal genes in Escherichia coli K-12 using PCR products. Proc Natl Acad Sci USA 2000, 97 (12):6640-6645.

44. Hapfelmeier S, Stecher B, Barthel M, Kremer M, Muller AJ, Heikenwalder M, Stallmach T, Hensel M, Pfeffer K, Akira S, et al: The Salmonella pathogenicity island (SPI)-2 and SPI-1 type III secretion systems allow Salmonella serovar typhimurium to trigger colitis via MyD88-dependent and MyD88-independent mechanisms. J Immunol 2005, 174(3):1675-1685.

45. Barthel M, Hapfelmeier S, Quintanilla-Martinez L, Kremer M, Rohde M, Hogardt M, Pfeffer K, Russmann H, Hardt WD: Pretreatment of mice with streptomycin provides a Salmonella enterica serovar Typhimurium colitis model that allows analysis of both pathogen and host. Infect Immun 2003, 71(5):2839-2858.

46. Suar M, Jantsch J, Hapfelmeier S, Kremer M, Stallmach T, Barrow PA, Hardt WD: Virulence of broad- and narrow-host-range Salmonella enterica serovars in the streptomycin-pretreated mouse model. Infect Immun 2006, 74(1):632-644.

47. Suar M, Periaswamy B, Songhet P, Misselwitz B, Muller A, Kappeli R, Kremer M, Heikenwalder M, Hardt WD: Accelerated type III secretion system 2-dependent enteropathogenesis by a Salmonella enterica serovar enteritidis PT4/6 strain. Infect Immun 2009, 77(9):3569-3577.
48. Endt K, Maier L, Kappeli R, Barthel M, Misselwitz B, Kremer M, Hardt WD: Peroral ciprofloxacin therapy impairs the generation of a protective immune response in a mouse model for Salmonella enterica serovar Typhimurium diarrhea, while parenteral ceftriaxone therapy does not. Antimicrob Agents Chemother 2012, 56(5):2295-2304.

49. Andrews FJ, Katz F, Jones A, Smith S, Finn A: CD40 ligand deficiency presenting as unresponsive neutropenia. Arch Dis Child 1996, 74(5):458-459.

50. Padigel UM, Alexander J, Farrell JP: The role of interleukin-10 in susceptibility of BALB/c mice to infection with Leishmania mexicana and Leishmania amazonensis. J Immunol 2003, 171(7):3705-3710.

51. Levine MM, Black RE, Lanata C: Precise estimation of the numbers of chronic carriers of Salmonella typhi in Santiago, Chile, an endemic area. J Infect Dis 1982, 146(6):724-726.

52. Hoffman TA, Ruiz CJ, Counts GW, Sachs JM, Nitzkin JL: Waterborne typhoid fever in Dade County, Florida. Clinical and therapeutic evaluation of 105 bacteremic patients. Am J Med 1975, 59(4):481-487.

53. Brodsky IE, Ernst RK, Miller SI, Falkow S: mig-14 is a Salmonella gene that plays a role in bacterial resistance to antimicrobial peptides. $J$ Bacteriol 2002, 184(12):3203-3213

doi:10.1186/1471-2180-13-236

Cite this article as: Pati et al:: Salmonella Typhimurium TTSS-2 deficient mig-14 mutant shows attenuation in immunocompromised mice and offers protection against wild-type Salmonella Typhimurium infection. BMC Microbiology 2013 13:236.

\section{Submit your next manuscript to BioMed Central and take full advantage of:}

- Convenient online submission

- Thorough peer review

- No space constraints or color figure charges

- Immediate publication on acceptance

- Inclusion in PubMed, CAS, Scopus and Google Scholar

- Research which is freely available for redistribution 